\title{
THE INSTRUCTION TO OVERCOME THE INERT KNOWLEDGE ISSUE IN SOLVING MATHEMATICAL PROBLEM
}

\author{
Febrian \\ febrianfebz@gmail.com \\ Mathematics Education - Teacher Training and Education Faculty \\ Maritime University of Raja Ali Haji \\ 2016
}

\begin{abstract}
One characteristic of typical mathematical problem is that it requires bunch of relevant prior knowledge. This knowledge is built consecutively and is recalled whenever needed to promote student to solve the problem. The process undertaken by the solver to utilize existing relevant prior knowledge while solving the problem is called access. However, this access is possible subject to disturbance for some reasons. This literature study addresses some factors that can distract access: factor related to metaprocess and factor related to deficit structure. The variants included in both factors have been proved through research as the contributors of the accessibility of relevant prior knowledge. Knowledge that cannot be accessed is called inert knowledge, the main reason for why solver face the difficulty to find the answer to given mathematical problem. The explanation leads to the suggestion of how to tackle the inertia of particular knowledge. One of them are through the instruction setting. Realistic Mathematics Education as one of approaches in learning can be a possible alternative for the issue of inert knowledge.
\end{abstract}

Keywords. Mathematical problem solving, prior knowledge, access, inert knowledge, Realistic Mathematics Education

\section{Introduction}

Consider the following case of multiplication of two two-digit numbers. The problem is about making small towers by using plastic blocks. There are 12 children in the class and each of them will be handed out 23 blocks. Then, the question that follows is to find the total number of blocks that will be used by all students in that project. By the time students tackle this problem, they have already learned the algorithm of multiplication of three-digit number and onedigit number (e.g., $128 \times 8$ ) and multiplication of 10 (e.g., $4 \times 30$ or $40 \times 3$ ). What will students possibly do to solve this problem?

The mathematical problem elaborated in those previous paragraphs is literally proposed by Nunokawa (2005). He took the problem from
Japanese 3rd grade Mathematics textbook. In this circumstance, one simple way the students probably do to solve this problem is by adding the number of each child's blocks. Students also may deal with the problem by drawing the situation itself, tower in this case, and count them in total.

Meanwhile, other students may notice that they can use multiplication for this problem situation since there are some sets of the same number of blocks. What may rise, however, is that they cannot apply what they know directly because they have not yet learned how to multiply two-digit numbers by two-digit numbers (for a review, see Nunokawa, 2005). Therefore, they need to explore the situation itself to find a contact point between their mathematical 
knowledge and the situation they are confronted with.

A contact point, as Nunokawa (2005) terms in this case, can be reached by the students who employ problem solving in which making partition on this multiplication case is taken into consideration. These students split 12 children into 10 children and the rest 2 children, for instance, and then the number of blocks for those 10 children can be calculated by $23 \times 10$ while the remaining 2 children's blocks can be obtained easily by $23 \times 2$. Both derived multiplications are included in mathematical knowledge they have already had.

This situation brings our view to what Lester \& Kehle (2003) define on the term mathematical problem solving. They define this term as a thinking process in which solver tries to make sense of problem situation by utilizing mathematical knowledge he/she has and attempts to obtain new information about that situation until he/she can "resolve the tension or ambiguity".

This definition implies that problem solving needs the solver to have prior knowledge related to the nature of the given problem. Moreover, this definition is in line with the view of knowledge theorists who argue that the important prerequisite knowledge must be activated when problem solving is carried out (Bransford et al, 1986). The question that follows is: what will be the case if the students do not use or even are not aware of the usefulness of relevant knowledge they have already had to solve the given mathematical problem?

As a consequence of this surfacing question, a process of utilizing the prior knowledge becomes one important thing to highlight. This process refers to what so-called access. In this case, a particular view argues that having the relevant prior knowledge towards the problem situation entails no guarantee for access to that knowledge to appear (Bransford and Johnson, 1972, Experiment 2; Dooling \& Lahman, 1971). To put in other way, the knowledge is seemingly available, but it is not often used, especially when problem solving is undertaken.

Moreover, the situation leads to the consideration of the phenomenon in which knowledge cannot be accessed nor it is used when solving particular mathematical problem, rather than ordinary questions in exams that need to be answered in instructional context. This kind of knowledge is labelled by Whitehead (1929) as "inert", its use of which is more and less confined to instructional contexts. Several explanations exist for this inert knowledge: metaprocess and structure deficit explanations (Renkl et al, 1996).

Metaprocess explanation assumes that the relevant knowledge is available, but it is not used because of the disturbed access process (e.g., lacking of metacognitive control). Structure deficit explanation supposes that the deficit is rooted in the structure of the knowledge itself.

To attack the occurrence of inert knowledge problem, several studies that concern on facilitating access are elaborated. Gick and Holyoak (1983) for instance, propose that students must be provided a support to a basis for inducing their schemata, the cognitive structure. Meanwhile, another study (Adams et al, 1985) concludes that the students must be situated in learning environment in which they can experience the problem. The students are also set to experience the usefulness of particular information to solve the problem. In addition to these studies, a particular instruction approach that shares many features with realistic problems of everyday life is proposed for its importance to students' constructing mathematical knowledge.

Sequentially, the learning approach that sets to overcome the inert knowledge through its contribution in facilitating access is proposed in this literature study. This learning approach, originally developed in Netherlands, is called Realistic Mathematics Education (RME). This approach aims at the construction by the children of their own mathematical knowledge by giving meaning to problems from real world context (for a review see Wubbles et al, 1997). Hence, the mathematical knowledge they construct can be used in other situations. 


\section{Access to the Knowledge}

Firstly, the explanation on the existence of the access and how it is related to the knowledge is elaborated. To see how they are related to each other, one case occurring when students are learning specific subject is discussed.

The information is generally presented as description of fact to be learned (Bransford et al, 1986). The students are collecting the new information as they learn something, one particular mathematical concept for instance, and this kind of information will be used in the next learning process. Further, that attained information will appear and function as such tools to solve the subsequent problem (for review see Dewey and Hanson, 1970). Hence, the process of solving problem will become easier.

Let us go back to mathematical problem posed by Nunokawa (2005) in the beginning of this writing. What students have already owned to solve the multiplication $23 \times 12$, which is something new for them to learn, is just the knowledge on multiplication of three-digit numbers with one-digit number and multiplication of ten. Under this occasion, the students will make an access to multiplication they have learned to solve the given new multiplication. As they explore what they know, they will see that the knowledge they have will help them to get the answer to $23 \times 12$ by splitting this multiplication into $23 \times 10$ and $23 \times 2$, both will sum up into the product of $23 \times 12$. In this case, it is obvious that access to prior knowledge is really helpful for them. Hence, what is underlined in this moment is the students need to know and understand the importance of prior knowledge as tool to tackle the given new problem.

However, the disturbance may appear when the students try to use their prerequisite knowledge to solve the given problem. The condition will be very much like the opposite of the Nunokawa's students answer. The students know that the number of blocks is represented by the product of the multiplication of $23 \times 12$, since they see that there are 12 groups of same number of blocks. But, they do not know how to solve 23 $\mathrm{x} 12$ even though they have potential prior knowledge to support their solving problem.

Consequently, it emerges the questions on how such condition can happen. This view is at last supported by the statements argued by Bransford \& Johnson (1972) and Dooling \& Lahman (1971) indicating the fact that acquired knowledge, which is relevant to particular situation, provides no guarantee that access will occur. In addition to that statement, there are also explanations concerning the knowledge and the access and both aspects' contribution to what socalled inert knowledge (Renkl et al, 1996). This kind of knowledge will be explained in this following section.

\section{The Explanations of Inert Knowledge}

One of the reasons why such prior knowledge cannot be accessed and is not used towards solving problem is disturbance on access. The explanation on why such disturbance may appear is then elaborated in this section.

First, let us refer to common phenomenon proposed by Bransford et al (1991) saying that knowledge learned in instructional setting, such as school, is not used outside the corresponding context. This phenomenon will lead to the situation in which students are only able to answer questions in exams, but not able to do so when dealing with the problem related to life or real life context situation. This situation will limit the knowledge of students since the knowledge itself only applicable in future, in certain possibly similar context they learned previously. It is bounded in other words. What comes next is that students cannot or even are not able to access prerequisite knowledge in other context. This situation is described in explanation of what Whitehead (1929) label as "inert" knowledge.

Consequently, several explanations on the existence of this knowledge become crucial to explore. These explanations are recognized as: metaprocess and structure deficit (Renkl et al, 1996). These explanations bring the ideas on why such the inertia of knowledge, the moment when knowledge become inert, may surface followed 
by several important aspects that need to take into account.

The first explanation is around metaprocess, which generally implies that the relevant knowledge is available, but it is not used because of the disturbed access process (Renkl et al 1996). There are several aspects underlined to the rise of disturbance which then be called important variants. These variants take worthwhile role in affecting the inertia of the knowledge. Renkl et al (1996) proposes two important variants which are metacognitive control and motivational factors.

Through the metacognitive explanation, the importance of what so-called conditional knowledge is counted in. It is referred to what argued by Paris, Lipson, and Wixson (1983) comprising that conditional knowledge is necessary for effective metacognitive control of knowledge application process. Conditional knowledge in this case is comprised to the knowledge of "when" and "why" to access certain fact, knowledge, or strategies. This view is then supported by Paris and colleagues (e.g., Paris \& Jacobs, 1984) saying that there is significant associations between awareness of the usefulness of strategies and text comprehension. What can be derived from these perspectives is that when students know or even are aware of when they use their prior knowledge and why they should use that knowledge, it means that they already open the opportunity to access to targeted applicable knowledge in case of solving given problem.

Furthermore, such a proof is carried out concerning the effect of conditional knowledge to the applicability of prior knowledge. A training aimed at informing the students about the use and usefulness of strategies or prior knowledge are designed (for a preview see Paris, Cross, \& Lipson, 1984; Paris \& Oka, 1986). The implementation of the concerned aspects, use and usefulness of strategies or knowledge in classroom proved to be successful to increase the strategy and the use of prior knowledge and text comprehension skill. Hence, knowing the importance of metacognitive control gives insight on how lacking of this variant can affect students' understanding on conditional knowledge.

The second variant of metaprocess explanation refers to motivational factors. The importance of this variant has been proved in several studies. Those studies have shown that interest and intrinsic motivation (an essential component of activated interest) are related to the application of learning strategies (e.g., Pintrich \& Garcia, 1991; for an overview, see Schiefele \& Schreyer, 1994). What can be attained through the study is that students who employ deep-level strategies are the ones who are highly interested to elaborate the learning materials, monitor their comprehension level and do not merely learn by rote. Moreover, study by Gruber \& Renkl (1994) shows that lacking of interest will give detrimental effect to strategy application in a long-term implication. After all, all those results imply that keeping students highly motivated and interested in learning situation will set them to learn and elaborate in deep way to get their understanding towards the knowledge.

The next explanations on the inertia of knowledge is on structure deficit. This explanation brings the idea that deficits in to-be applied knowledge are responsible for its missing application or access. There two variants discussed by Renkl (1996). They are variants referring to lacking knowledge compilation and to knowledge compartmentalization, respectively.

The lacking knowledge compilation brings the concept of declarative knowledge (knowing what) and procedural knowledge (knowing how). This variant argues that within instructional settings, declarative knowledge is fostered primarily even though it is considered to be not directly applicable (Anderson, 1987). The theory by Anderson (1987) is taken into account to create an acquisition of effective and efficient procedural knowledge. In respect to that, three stages are proposed. First, interpretative stage, implies that weak procedure must bring on the declarative knowledge. The repetition on this weak 
procedure will lead to the second stage, which is termed as knowledge compilation. In this level, a procedural representation of skill is generated (for a preview see Anderson, 1983). Hence, the applicability of knowledge is reached. In the last stage, the skill is more tuned especially in process of generalization, discrimination, and strengthening. Moreover, these three stages imply the conditionalizing knowledge which produces the term conditionalized knowledge in which Anderson (1983) relates to the application condition of knowledge. Point to remember is that conditionalized knowledge in this case is totally different with conditional knowledge in first variant of metaprocess explanation.

$$
\text { Regarding the importance }
$$

of conditionalized knowledge, certain kind of instruction in which the knowledge is possibly developed, is then taken into consideration. Let us propose what argued by Bransford (1991) describing that conditionalized knowledge is seldom to achieve in traditional form of instruction since application of knowledge is rarely taught in the school, it makes the knowledge itself is hardly learned. What can be surfaced as consequence is that a direct applicability of knowledge is hardly to achieve.

Meanwhile, the second variant to this structure deficit explanation brings the idea that the inertia of knowledge raises when students do not connect their subject matter learned in the school with their everyday life (Alexander \& Murphy, in press). This explanation is then termed by Mandl et al (1993) and Schoenfeld (1986) as knowledge compartmentalization.

The idea to this explanation is that knowledge learned in the school and everyday life experiences are put in different memory compartment, and both compartments lack of connection.

To draw the situation in a more understandable way, one of the mathematical problem (Silver, 1986, p. 192) presenting the context of buses and passengers is discussed. It is said that there are 130 students and one bus contains 50 passengers. The question asks the students to find the number of buses which will be hired. Four answers are provided to students to choose which are 2, 2.5, 2.6, and 3. Silver (1986) found in 1983, $35 \%$ of American students answered correctly while the rest of them chose the answer 2.5 which is obtained by simply dividing 130 with 50 . The analyses conducted shows that students fail to recognize that the number of buses cannot be fraction at all. It is obvious that students do not connect their problem to their daily life experiences that lead them into mistake. Seeing this situation, knowledge compartmentalization does not give opportunity to transfer context learned in the school to other context such as the ones in their daily life. Hence, the effort to overcome the problem of inert knowledge seems important to have. The following section will explain how the inert knowledge can be tackled.

\section{Tackling the Inert Knowledge Issue}

The previous discussion has revealed some factors that can impede knowledge application or disturb access to the relevant prior knowledge. The explanations towards the existence of inert knowledge have also opened the opportunity to avoid the detrimental effect flourished by the inert knowledge itself. One of the attempts that can be conducted is doing the training on seeing the use and usefulness of such strategy and knowledge. To support the understanding on "when" and "why", such strategy or knowledge is used or access just like what implemented by Paris et al (for a preview see Paris, Cross, \& Lipson, 1984; Paris \& Oka, 1986). Meanwhile, another way to solve the inert knowledge problem is derived from instruction setting.

In addition to that, such an instruction has to be designed in way that explicitly attacks this inert knowledge problem (Renkl, 1996). One way that can be considered is creating the instruction in which experience that provides a basis for inducing relevant schemata, is generated (Gick and Holyoak, 1983).

Based on schema theory, students' knowledge base is not only conceptual and procedural knowledge, but also the knowledge about typical situations in which targeted knowledge is applied (Nunokawa, 2005). The 
knowledge base stated in this theory is a structure, and this structure is defined as schemata. To be precise, Owen and Sweller (1985) define this as a cognitive structure that allows a problem solver to categorize a problem and then to indicate the most appropriate moves for problems of that class. This definition implies that schemata is something important to have and to enhance by the students to make them recognize what problem wanting them to do as well as to prepare the appropriate way, strategy or prior knowledge to tackle the problem. Schemata can be enhanced by setting the students to pass through the problem solving experience in which the students learn a rich body of schemata itself (Nunokawa, 2005).

Moreover, to attack the problem of inert knowledge, it is important not only to set students to experience problems, but also to set them to experience the usefulness of knowledge they learn. This is what implied by Adams et al (1985) based on his study which illustrates that how access is facilitated by learning activities that help students experience problem and then experience the usefulness of information for solving those problems. It is also noticed that the important aspect like facing students with real life context within mathematical problem is possibly triggered to against the lacking of connection, in compartmentalization knowledge, between what students learn in the school with their everyday life experiences.

One of the instruction approaches that proposes real life problem that is closely related to the students to explore is Realistic Mathematics education (RME).

\section{Realistic Mathematics Education (RME)}

RME approach aims at the construction by children of their own mathematical knowledge by giving meaning to problems from real world context (Freudenthal, 1978; Treffers, 1987). In this set of learning, teachers help students to develop their informal strategies into more formal approaches in which they can use in other situations (Treffers, 1987). This implies that RME provides students to explore what they know to construct their own knowledge that can be used to subsequent learning through solving the problem.

In addition to that, problem is derived in real world context. But in this case, the problem must fit the particular realistic criterion. The criterion for problem to be called realistic is it should be likely that the problem is experienced by the learner as real and personally interesting (Wubbles et al, 1997).

Furthermore, RME does not start from abstract principles or rules with the aim to learn to apply these rules in concrete situations, nor does it focus on an instrumental type of knowledge (Wubbles et al, 1997). In addition, what is underlined in this approach is that students themselves undergo the process of constructing knowledge and principles. As Freudhental (1978) puts it, it reflects a shift from mathematics as a created subject towards mathematics as a subject to create. This reveals the more dynamic view of mathematics in which mathematical actions and the process of developing strategies are given more attention. Finally, Freudhental (1991) emphasizes that this approach enables students to have opportunity to 'reinvent' mathematical ideas.

This approach, developed in school mathematics in Netherlands, gives outstanding contribution in mathematical attainment. This is proved by two major international comparative studies which are PISA (Programme for International Student Assessment) and TIMSS (Trends in International Mathematics and Science Study). Another former compares students' mathematical problem solving abilities and is administered by the OECD. What is attained that Netherlands students usually scores well above average in both tests.

\section{Conclusion}

It can be derived that there are two aspects on realistic problem, which are real and personally interesting. Facing the students to real daily life problem in classroom learning will enable students to connect their subject matter being learned to that in their daily life. Furthermore, giving students the opportunity to explore the connection between what they learn 
and what they face in everyday life will solve the inertia of knowledge being proposed by Alexander and Murphy. This view also counters the existence of knowledge compartmentalization implying that knowledge students get in school and their everyday life experience are put in different compartment which lacks of connection.

Another remarkable point of view is that problem derived should be (personally) interesting. This implies that problem must be able to raise students' interest in solving that problem itself. As elaborated, interest is one variant in metaprocess knowledge that is important to have to tackle the problem of inert knowledge.

Finally, considering RME as one of the instructions to be apply in mathematics classroom learning will give positive effect towards students' schemata or cognitive structure since they pass the process of constructing knowledge by themselves through real problem that set to raise their interest in solving it. As students solve the problem, a consequence to that, is the access to the applicable relevant prior knowledge that will be about to happen. For that case, the existence of inert knowledge might be tackled.

\section{References}

Adams, L. T., Perfetto, G. A., Yearwood, A., Kasserman, J., Bransford, J. D., \& Franks, J. J. (1985). Facilitating access. Unpublished manuscript, Vanderbilt University.

Anderson, J. R. (1983). The architecture of cognition. Cambridge, MA: Harvard University Press.

Anderson, J. R. (1987). Skill acquisition: Compilation of weak-method problem solutions.Psychological Review, 94, 192210.

Bransford, J., Sherwood, R., Vye, N., \& Rieser, J. (1986)Teaching thinking and problem solving. American Psychology, 1078-1088

Bransford, J. D., Goldman, S. R., \& Vye, N. J. (1991). Making a difference in people's ability to think: Reflections on a decade of work and some for the future. In R. J.
Sternberg \& L. Okagaki (Eds.), Influences on children (pp. 147-180). Hillsdale, NJ: Lawrence Erlbaum Associates, Inc.

Freudenthal, H. (1978). Weeding and Sowing. Preface of a Science of Mathematics Education. Reidel. Publishing Company, Dordrecht.

Freudenthal, H. (1991). Revisiting Mathematics Education: China Lectures, Kluwer, Dordrecht/Boston/London.

Gick, M.L., \& Holyoak, K. J. (1983). Schema induction and analogical transfer. Cognitive Psychology, 15, 1-38

Hanson, N. R. (1970). A picture theory of theory meaning. In R. G. Colodny (Ed.), The nature and function of scientific theories (pp.233274). Pittsburgh, PA: University of Pitsburgh Press.

Lester, F. K., Jr., \& Kehle, P. E. (2003). From problem solving to modeling: The evolution of thinking about research on complex mathematical activity. In R. Lesh \& H.M. Doerr (Eds.),Beyond constructivism: Models and modeling perspectives on mathematics problem solving, learning, and teaching (pp. 501-517). Mahwah, NJ: Lawrence Erlbaum.

Mandl, H., Gruber, H., \& Renkl, A. (1993). Misconceptions and knowledge compartmentalization. In G. Strube \& F. Wender (Eds.), The cognitive psychology of knowledge (pp. 161-176). Amsterdam: North-Holland.

Nunokawa,K. (2005). Mathematical problem solving and learning mathematics: What we expect students to obtain. Journal of Mathematical Behaviour 24 (2005), 325340.

Owen, E., \& Sweller, J. (1985). What do students learn while solving mathematics problems? Journal of Educational Psychology, 77(3), 272-284.

Paris, S. G., Cross, D. R. \& Lipson, M. Y. (1984). Informed strategies for learning: A program to improve children's reading awareness and comprehension. Journal of Educational Psychology, 76, 1239-1252.

Paris, S. G. \& Jacobs, J. E. (1984). The benefits of informed instruction for children's reading 
awareness and comprehension skills, Child Development, 55, 2083-2093.

Paris, S. G., Lipson, M. Y., \& Wixson, K. K. (1983). Becoming a strategic reader.Contemporary Educational Psychology, 8, 293-316.

Paris, S. G., \& Oka, E. R. (1986). Children's reading startegies, metacognition and motivation. Developmental Review, 6, 25-26.

Pintrich, P. R., \& Garcia, T. (1991). Student goal orientation and self-regulation in the college classroom. Advances in Motivation and Achievement, 7, 371-402

Renkl, A., Gruber, Mandl, H., \& Hinkofer, L. (1994). Hilft Wissen beider Identification und Steuerung eines komplexen okonomischen Systems?(Does knowledge support identification and control of a complex economical system?) Unterrichtswissenschaft, 22, 195202.

Renkl, A., Gruber, Mandl, H., \& Hinkofer, L. (1996). Inert knowledge: Analyses and remedies. Educational Psychologist, 31(2), 115-121.

Schiefele, U., \& Schreyer, I. (1994). Intrinsische Lernmotivation und Lernen. Ein Uberblick $\mathrm{zu}$ Ergebnissen der Forschung (Intrinsic motivation and learning. An overviewof research results). Zeitschrift fur Padagogische Psychologie, 8, 1-13.

Schoenfeld, A. H. (1986). On having and using geometric knowledge. In J. Hiebert (Ed.),Conceptual and procedural knowledge: The case of mathematics (pp. 225-264). Hillsdale, NJ: Lawrence Erlbaum Associates, Inc.

Silver, E. A. (1986). Using conceptual and procedural knowledge: A focus on relationships. In J. Hiebert (Ed.), Conceptual and procedural knowledge: The case of mathematics (pp. 181-198). Hillsdale, NJ: Lawrence Erlbaum Associates, Inc.

Treffers, A. (1987), 'Three Dimensions', A Model of Goals and Theory Description in Mathematics Instruction - TheWiskobas
Project,Reidel Publishing Company, Dordrecht.

Whitehead, A. N. (1929). The aims of education. New York: Macmilan.

Wubbels, Th., Korthagen, F., and Broekman, H. (1997), Preparing Teacher for Realistic Mathemtics Education, Kluwer Academic Publishers, Netherlands. 